\title{
Child Labor and Resistance to Change*
}

\author{
Giorgio Bellettini \\ University of Bologna \\ Carlotta Berti Ceroni \\ University of Bologna \\ Gianmarco I.P. Ottaviano \\ University of Bologna and CEPR
}

May 15, 2003

\begin{abstract}
We study the interactions between technological innovation, investment in human capital and child labor. In our setting new technologies require new skills and new skills can be developed only through schooling. In a two-stage game, first firms decide on innovation, then households decide on education. In equilibrium the presence of inefficient child labor depends on parameters related to technology, parents' altruism and the diffusion of firm property. When child labor exists, it is due to either firms reluctance to innovate or households' unwillingness to educate or both. The optimal policy to eliminate child labor depends crucially on its underlying cause. We show that, in some cases, compulsory schooling laws or a ban on child labor are welfare reducing, while a subsidy to innovation is the right tool to eliminate child labor and increase welfare.

Keywords: child labor, innovation;

JEL classification: J24, O31.
\end{abstract}

${ }^{*}$ We would like to thank Jean Marc Tallon and seminar participants at EUREQUA for useful comments. All remaining errors are ours. Corresponding author: Carlotta Berti Ceroni, Dipartimento di Scienze Economiche, Università di Bologna, P.zza Scaravilli 2, Bologna 40126, Italy. E-mail: bceroni@economia.unibo.it 


\section{Introduction}

According to International Labor Organization statistics (see ILO [11]), in 1995 at least 120 millions of children between five and twelve years of age worked full time in paid jobs, mostly in underdeveloped regions. This figure would at least double if we took into account children who work part-time. These impressive statistics awake concern both in developing and developed countries and command theoretical as well as policy-oriented analysis. In June of 1999 the 174 member nations of the ILO passed an international convention, upon ratification of which member states are pledged to eliminate the worst forms of child labor immediately and to end, in the long run, all forms of child labor.

A central question for national governments and international organizations is therefore how to intervene in order to reduce the extent of the phenomenon. Indeed, from the point of view of economic theory, public intervention should be justified either by efficiency arguments (for example, in the presence of some kind of externalities or coordination failures) or by social preferences that call for some form of redistribution in favor of children and possibly poor households. Moreover, whatever the justification is, it is clear that any government intervention aimed at reducing or eliminating child labor will affect the current and future welfare of children and is likely to have relevant spillovers on others. It is therefore very important to better understand the determinants of child labor and design policy interventions upon careful analysis and research.

Since the publication of a recent paper by Basu and Van [3], there has been a surge of interest among economists for the theoretical investigation of the causes of child labor aiming at assessing the desirability and efficacy of alternative remedies. However, almost all contributions have so far dealt with the determinants of the supply of (child) labor, focusing mainly on the role of poverty, fertility and liquidity constraints. ${ }^{1}$ Furthermore, many of these contributions fail to give a clear-cut argument on the efficiency properties of child labor and the welfare effects of government intervention in this area.

This paper contributes to the literature on the economics of child labor by focusing on the analysis of the determinants of the firm's demand for unskilled (child) labor versus more skilled labor and its interaction with the educational choices of households. In fact, it is widely recognized by economic historians that in many circumstances the reduction or elimination of child labor has been driven by technological progress and the substitution of adult and educated workers for young and unskilled workers (for historical examples,

\footnotetext{
${ }^{1}$ See for example Baland and Robinson [1], Bellettini and Berti Ceroni [4], Cigno and Rosati [5], Dessy [6], Ranjan [14] and Swinnerton and Rogers [15], [16]. An exhaustive survey of the literature on the economics of child labor can be found in Basu [2].
} 
see Galbi [9], Levy [12] and Weiner [17]).

In order to tackle these issues, we develop a model that studies the relationship between technological innovation, child labor and investment in human capital. In a two-period economy, we analyze the joint decisions of altruistic parents (who must decide whether to send their children to work or to school) and firms (which must decide whether to switch to a new technology or not). These decisions are closely interrelated since the returns to education depend on the level of technology and, in turn, the profitability of innovation depends on the quality and skills of the labor force.

More specifically, we assume that technological innovation is decided by the owners of a monopolistic firm. Innovation entails the adoption of a new vintage technology with lower marginal costs of production. However, the adoption of the new vintage implies that the old one becomes freely available to competitors ${ }^{2}$. Moreover, for the new vintage to become operative it is necessary that the labor force acquires the adequate skills or, in other words, that children go to school.

The equilibrium of the model is defined as the outcome of a sequential game where the owners of the monopolistic firm ('capitalists') move first and decide simultaneously whether to innovate or not and whether to send their children to school or work. After observing the capitalists' move, workers decide whether to send their own children to school or work. We show that our economy always displays a unique subgame perfect equilibrium, whose features depend on the value of parameters related to the technology, the degree of parents' altruism and the degree of diffusion of firm's property. When child labor appears in equilibrium, that is due to either firm's reluctance to innovate or workers' unwillingness to educate or both.

Focusing on situations in which child labor is inefficient, we argue that the adequate policy intervention (whether compulsory schooling laws, ban on child labor, subsidies to innovation or to education, etc.) depends crucially on the underlying causes. In particular, we point out circumstances in which the introduction of compulsory schooling laws or a ban on child labor are both welfare reducing, while a subsidy to innovation succeeds in both eliminating child labor and increasing welfare.

Recent work by Dessy and Pallage [7] also stresses the complementarity between simultaneous decisions on technology adoption and skill accumulation. In their case such

\footnotetext{
${ }^{2}$ To justify this assumption we could imagine that the information contained in the patent protecting the state-of-the-art technology allows competitors to imitate the previous vintage technology without breaking the patent. In a different context, Dinopoulos and Segerstrom [8] make the similar assumption that previously patented products can be competitively produced by firms when further innovation occurs in the same industry.
} 
complementarity gives rise to a multiplicity of Pareto-rankable Nash equilibria so that a coordination failure between firms and households may support a suboptimal outcome with technological stagnation and child labor. In our case, multiple equilibria are not part of the story. On purpose, they are avoided by the sequential structure of the game: there is always a unique subgame perfect equilibrium. Accordingly, self-fulfilling 'bad' expectations are not the cause of child labor. Consequently, we are able to push our policy analysis beyond helping 'good' expectations to coordinate.

The rest of the paper is organized as follows. Section 2 introduces the model. Section 3 characterizes the efficient outcome. Section 4 describes the equilibrium outcome. Section 5 presents comparative statics results. Section 6 discusses policy implications and section 7 concludes.

\section{The model}

We consider a two-period economy, populated by a continuum of identical households of measure 1. In the first period (period $t$ ) each household consists of 1 adult and $n \geq 1$ children for a total of $n+1$ individuals. Adults live for one period, children for two, so that only children are alive in the second period (period $t+1$ ) and the household dimension shrinks to $n$. Each individual is endowed with 1 unit of time per period. While adults supply their units of time inelastically to the labor market, children can choose whether to work or to go to school. The decision on children's time use is made by their altruistic parents. Education is free of charge so that its only (indirect) cost is the foregone labor income of children. The benefit of education comes from human capital accumulation that, in the second period, will allow grown-up children to operate more sophisticated technologies.

On the demand side, due to altruism, the preferences of a typical adult (and thus of the corresponding household) are represented by an intertemporal utility function defined over the consumption of a unique homogeneous good. Specifically, utility is assumed to be linear in the amounts consumed in the two periods:

$$
U=(1+n) c_{t}+\rho n c_{t+1}
$$

where $c_{t}$ is consumption at time $t$ and $\rho \in(0,1)$ is the discount factor. There are no capital markets so that in each period expenditures equal income. ${ }^{3}$

\footnotetext{
${ }^{3}$ Given linear utility, in our model the absence of capital markets is not the source of child labor but only a simplifying (realistic) assumption. For an analysis in which child labor arises due to credit constraints see Ranjan [14].
} 
On the supply side, we adopt the dual-technology model of Murphy, Shleifer, and Vishny [13] and we adapt it to our intertemporal setting. In the first period, two technologies, 'traditional' and 'modern', are available for the production of the unique consumption good. Both technologies are linear and use labor as their only input. They differ, however, in terms of productivity, the modern technology being more productive than the traditional one. While the traditional technology is freely disposable, the modern one is exclusive property of one firm only. Due to free disposal, when active, the traditional technology is operated by perfectly competitive firms that are publicly and equally owned by all households. On the contrary, the ownership of the modern firm is equally shared only by a fraction $\theta$ of the households ('capitalists'), with $\theta \in[0,1]$.

Specifically, we assume that, when employed in the traditional technology, one unit of labor produces $\alpha_{0}$ units of good, while it produces $\alpha_{1}>\alpha_{0}$ units of good when employed in the modern one. Choosing labor as numeraire, this implies that in the former case the marginal cost of production is $1 / \alpha_{0}$ while in the latter it is $1 / \alpha_{1}<1 / \alpha_{0}$.

Profit maximization leads the modern firm to exploit its cost advantage in order to prevent traditional firms from entering the market at all. In particular, this is achieved through limit pricing, that is, by setting a price at which traditional firms are just indifferent between operating or not. That implies that in equilibrium the modern firm's price equals the marginal cost of traditional firms:

$$
p_{t}=1 / \alpha_{0}
$$

The result is, thus, that the modern firm operates as a monopolist and earns nominal profits:

$$
\Pi_{t}=\left(p_{t}-1 / \alpha_{1}\right) y_{t}
$$

where $y_{t}$ is its output and the term between parentheses is the price-cost margin. In real terms, profits can be rewritten as:

$$
\pi_{t}=\frac{\Pi_{t}}{p_{t}}=\frac{1 / \alpha_{0}-1 / \alpha_{1}}{1 / \alpha_{0}} y_{t}=\frac{\alpha_{1}-\alpha_{0}}{\alpha_{1}} y_{t}
$$

This leads to aggregate nominal and real incomes that are respectively:

$$
\begin{gathered}
Y_{t}=p_{t} y_{t}=\left(1 / \alpha_{0}\right) y_{t}=\Pi_{t}+N_{t} \\
y_{t}=\pi_{t}+\alpha_{0} N_{t}
\end{gathered}
$$

where $N_{t}$ is the total number of individuals (adults plus children) who work at time $t$. 
Solving the system formed by (4) and (6), we obtain the following expression for profits and income in real terms:

$$
\begin{gathered}
\pi_{t}=\left(\alpha_{1}-\alpha_{0}\right) N_{t} \\
y_{t}=\alpha_{1} N_{t}
\end{gathered}
$$

In the first period the monopolist, and thus the capitalists, also face an intertemporal decision in that they can decide whether to update the modern technology or not. If they do, the 'updated' technology will be ready for production in the second period with productivity $\alpha_{2}>\alpha_{1}>\alpha_{0}$. However, its operation by grown-up children will be possible only if they have attained an adequate level of human capital through education in the first period. In other words, the capitalists as well as the other households (henceforth called simply 'workers') face a second intertemporal decision on whether to educate their children or not and the updated technology will be implementable only if the innovation decision of the monopolist is matched by the education decision of the households.

More precisely, we assume that the capitalists move first in anticipation of households' choices. The exact timing of events is the following. At the beginning of period $t$, the capitalists as a group decide whether to update $(I)$ or not $(N I)$ as well as whether to send their children to school $\left(E^{o}\right)$ or not $\left(N E^{o}\right)$. Then, the workers decide whether to send their children to school $(E)$ or not $(N E)$. After that, during period $t$, production, education (if any) and consumption take place. Finally, at the end of period $t$, adults pass away. At the beginning of period $t+1$, if capitalists have previously decided to update, the new technology becomes available to the monopolist only while the outdated one becomes freely available. Lastly, production and consumption by grown up children take place.

\section{The efficient outcome}

We are interested in investigating child labor as a market failure. To do so, we need to assess under which conditions child labor is inefficient. Our welfare measure is the sum of the indirect utilities of all capitalits and workers. Given linear utility this corresponds to the present value of aggregate output $y_{1}+\rho y_{2}$.

Straightfoward calculations show that:

Proposition 1 Aggregate welfare is maximized at either $\left(I, E^{o}, E\right)$ or $\left(N I, N E^{o}, N E\right)$. The former dominates the latter if and only if

$$
\alpha_{2} / \alpha_{1}>1+1 / \rho
$$


Intuitively, a planner would choose to send all children to school and to update the technology whenever the present value of the increase in future output due to innovation offsets the current loss of production due to education. Notice that the parameter $\alpha_{0}$ is irrelevant for the planner's choice because it affects the distribution of income but it does not affect the output increase.

In what follows we assume (9) to hold, that is, we focus on situations in which, when child labor emerges in equilibrium, it is inefficient so that there is scope for welfareimproving policy intervention.

\section{The equilibrium}

We are now ready to investigate the conditions under which the market outcome is caracterized by inefficient child labor. Specifically, we look for the Subgame Perfect Equilibrium (SPE) of the two-stage game of complete and perfect information between capitalists and workers. As we discussed above, capitalists move first. Their chosen action will be denoted by $a^{o}$. After having observed the action of the capitalists, workers choose their own favorite action $a$. Clearly, $a^{o}=\left(a_{1}^{o}, a_{2}^{o}\right)$ where $a_{1}^{o} \in A_{1}^{o}, a_{2}^{o} \in A_{2}^{o}, A_{1}^{o}=\{I, N I\}$ and $A_{2}^{o}=\left\{E^{o}, N E^{o}\right\}$. Similarly, $a \in A$ where $A=\{E, N E\}$.

Figure 1 summarizes the tree of the strategic interaction between capitalists and workers with the eight possible outcomes. The associated payoffs are the indirect utilities of the two interest groups, capitalists (labeled again by ${ }^{o}$ ) and workers (no label), calculated from (1). To derive them, the crucial thing to keep in mind is that for the updated technology to be operative in the second period, some children must attend school in the first period, in which case their current real labor income $\left(\alpha_{0} n\right)$ is traded against higher future real labor income $\left(\alpha_{1} n\right)$. Obviously, this also implies trading off current real profit against higher future real profit for the monopolist, since children attending school are withdrawn from production in the first period. The eight payoffs of workers $(A, B, C, D, E, F, G, H$, $K)$ and the eight payoffs of capitalists $\left(A^{o}, B^{o}, C^{o}, D^{o}, E^{o}, F^{o}, G^{o}, H^{o}, K^{o}\right)$ are reported in the Appendix. 


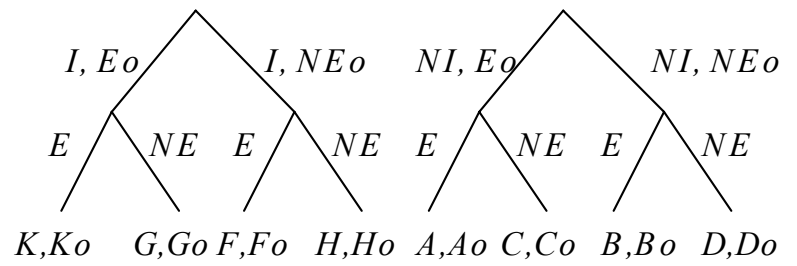

Figure 1: The extensive-form representation of the game

\subsection{The choice of workers}

Let us characterize the SPE by backward induction taking into account the extensive form depicted in Figure 1. After observing capitalists' decisions regarding innovation and education, workers must decide whether to send their children to school $(a=E)$ or not $(a=N E)$. Here we can distinguish between three cases.

1. Given $a^{o}=\left(N I, E^{o}\right)$ or $a^{o}=\left(N I, N E^{o}\right)$ workers' optimal response is $a=N E$ since $C>A$ and $D>B$. Intuitively, when capitalists do not innovate, the future real wage is equal to the current one $\left(\alpha_{0}\right)$, since the output price remains constant $\left(1 / \alpha_{0}\right)$. Workers have therefore no incentive to send children to school, since this would imply a loss in current labor income against a zero gain in future labor income.

2. Given $a^{o}=\left(I, N E^{o}\right)$, workers' optimal response is $a=N E$ since $F<H$. If capitalists innovate but do not send their children to school, they will be unable to operate the up-dated technology unless workers send their children to school. However, workers have no incentives to do so, since they anticipate that the future real wage will be higher in any case. The reason is the following. If workers' children get educated at time $t$, the monopolistic firm will be able to operate the updated technology at time $t+1$ and set the product price at $1 / \alpha_{1}$, so that the real wage will be equal to $\alpha_{1}$. Otherwise, the monopolistic firm will be unable to operate the up-dated technology at time $t+1$. Nonetheless, since innovation makes the modern technology freely disposable, a competitive fringe of firms will step in using that technology and the real wage will be still equal to $\alpha_{1}$. 
3. Given $a^{o}=\left(I, E^{o}\right)$, workers' optimal response is $a=E$ if and only if $K>G$, that is if and only if $\rho \alpha_{1}>\alpha_{0}$. If capitalists innovate and send their children to school they will operate the updated technology at time $t+1$ no matter what workers do. In order to decide whether to send their children to school or work at time $t+1$, workers must compare the loss in terms of current labor income (opportunity cost of education), $\alpha_{0}$, with the discounted net gain in terms of future labor income, which is given by $\rho \alpha_{1}$ since in this case only educated workers can be employed at time $t+1$.

Thus, for workers to be willing to send their children to school it must be $\rho \alpha_{1}>\alpha_{0}$.

\subsection{The choice of capitalists}

We can now turn to the characterization of capitalists' best course of action, given workers' best responses. Capitalists must take two simultaneous decisions: whether to adopt the new vintage technology $\left(a_{1}^{o}=I\right)$ or not $\left(a_{1}^{o}=N I\right)$ and whether to send their children to school $\left(a_{2}^{o}=E^{o}\right)$ or not $\left(a_{2}^{o}=N E^{o}\right)$.

It is immediate to verify that, anticipating workers' best responses, capitalists always prefer $a^{o}=\left(N I, N E^{o}\right)$ to $a^{o}=\left(N I, E^{o}\right)$, since $D^{o}>C^{o}$ and $B^{o}>A^{o}$. Intuitively, if capitalists decide not to update the modern technology, in their role of workers they will have no incentives to send their children to school, since this would imply a loss in terms of current labor and profit income against a zero gain in terms of future labor and profit income.

By the same token, $a^{o}=\left(N I, N E^{o}\right)$ is preferred to $a^{o}=\left(I, N E^{o}\right)$ since $D^{o}>H^{o}$. As we know, if capitalists innovate but do not send children to school, workers will not send children to school either so that capitalists will be unable to operate the new technology in period $t+1$ but, at the same time, also to prevent the entry of the competitive fringe. For $\theta<1$, if the capitalists send their children to school, the ensuing loss in terms of discounted profit income, $\rho\left(\alpha_{1}-\alpha_{0}\right) n$, is always larger than the gain in terms of discounted wage income, $\theta \rho\left(\alpha_{1}-\alpha_{0}\right) n$.

Therefore, we can conclude that

Remark 2 In equilibrium children never attend school in the absence of innovation and innovation is impossible unless some children go to school.

Once we have eliminated actions $a^{o}=\left(N I, E^{o}\right)$ and $a^{o}=\left(I, N E^{o}\right)$, we can finally analyze the capitalists' choice between action $a^{o}=\left(I, E^{o}\right)$ and $a^{o}=\left(N I, N E^{o}\right)$. Different scenarios emerge depending on workers' willingness to send their children to school, that is depending on the relation between $\rho \alpha_{1}$ and $\alpha_{0}$. 
1. When $\rho \alpha_{1}>\alpha_{0}$, capitalists prefer $a^{o}=\left(I, E^{o}\right)$ to $a^{o}=\left(N I, N E^{o}\right)$ if and only if $K^{o}>D^{o}$, that is if and only if:

$$
(1 / \theta)\left[\rho\left(\alpha_{2}-\alpha_{1}\right)-(1+\rho)\left(\alpha_{1}-\alpha_{0}\right)\right] n+\left[\rho \alpha_{1}-(1+\rho) \alpha_{0}\right] n>0
$$

In words, if the discounted future income gain in terms of higher profits, that is $\rho\left[\left(\alpha_{2}-\alpha_{1}\right)-\left(\alpha_{1}-\alpha_{0}\right)\right] n$, and higher wages, $\rho\left(\alpha_{1}-\alpha_{0}\right) \theta n$, is larger than the opportunity cost of innovation in terms of current income $\left[\left(\alpha_{1}-\alpha_{0}\right)+\theta \alpha_{0}\right] n$, capitalists will innovate and send their children to school. As we know, this in turn implies that workers will also send children to school, so that $\left(I, E^{o}, E\right)$ would be the SPE of the game.

If condition (10) is not satisfied, capitalists do not innovate and nobody sends children to school, so that $\left(N I, N E^{o}, N E\right)$ is the SPE of the game. Notice that in this case child labor emerges as a consequence of capitalists' resistance to innovation as well as to education and hurts workers who would have been better off had the firm innovated.

2. When $\rho \alpha_{1}<\alpha_{0}$ (i.e. when workers never send children to school), capitalists prefer $a^{o}=\left(I, E^{o}\right)$ to $a^{o}=\left(N I, N E^{o}\right)$ if and only if $G^{o}>D^{o}$, that is if and only if:

$$
(1 / \theta)\left[\rho \theta\left(\alpha_{2}-\alpha_{1}\right)-(\theta+\rho)\left(\alpha_{1}-\alpha_{0}\right)\right] n+\left[\rho \alpha_{1}-(1+\rho) \alpha_{0}\right] n>0
$$

The net gain from profits following innovation is different with respect to the preceding case since only capitalists' children go to school at time $t$ (implying a smaller loss in current profit) and work at time $t+1$ (implying a smaller gain in future profits). In this case, the SPE equilibrium of the game would be $\left(I, E^{o}, N E\right)$, implying innovation and 'partial' child labor: only capitalist offsprings go to school.

If condition (11) is not satisfied, capitalists do not innovate and nobody sends children to school, so that $\left(N I, N E^{o}, N E\right)$ is the SPE of the game. In this case, both workers and capitalists resist education.

In order to summarize the above results, it is useful to provide a graphical representation of the possible equilibrium outcomes. Denote with $E E, I I$ and $I E^{o}$ the loci defined respectively by the following equations:

$$
\begin{gathered}
\frac{\alpha_{1}}{\alpha_{0}}=\frac{1}{\rho} \\
\frac{\alpha_{2}}{\alpha_{1}}=1-\theta+\frac{1+\rho}{\rho}-(1-\theta) \frac{1+\rho}{\rho} \frac{1}{\alpha_{1} / \alpha_{0}} \\
\frac{\alpha_{2}}{\alpha_{1}}=\frac{\rho+\theta}{\rho \theta}-\frac{1-\theta}{\theta} \frac{1}{\alpha_{1} / \alpha_{0}}
\end{gathered}
$$


in the $\left(\alpha_{1} / \alpha_{0}, \alpha_{2} / \alpha_{1}\right)$ space. Notice that $I I$ and $I E^{o}$ are derived by equations (10) and (11). Figure 2 depicts the three loci for $0<\theta<1$ and $\theta+\rho<1$ in the relevant area defined by $(9)$.

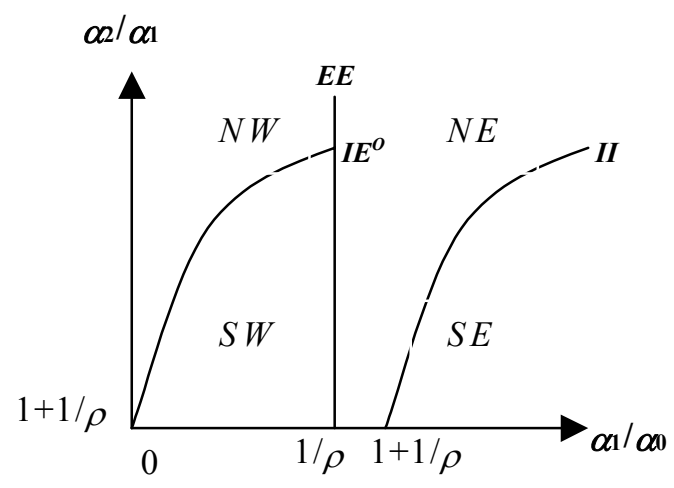

Figure 2: The equilibrium $(0<\theta<1)$

By inspection of Figure 2, we can restate the above results as follows:

Proposition 3 The II,EE and IE loci identify four regions. To the left of EE, there is partial child labor (only capitalists' children go to school) above the IE ${ }^{o}$ locus (region $N W$ ) and complete child labor below it (region $S W$ ). To the right of EE, there is no child labor above the II curve (region NE) and complete child labor below it (region SE).

Notice that, while in region $S E$ child labor is the result of firm's resistance to innovation (since the price-cost margin after innovation is low relative to the current one), in region $S W$ both workers and capitalists resist education and innovation (also the wage increase is low). Moreover, even if in region $N W$ the (profit) gain from innovation is high enough to make updating beneficial for the capitalists, wage growth following innovation is not high enough to make education beneficial for the workers. In this case, child labor occurs among workers notwithstanding firm's willingness to innovate.

\section{The role of property diffusion}

Let us now analyze how the equilibrium characterization depends on the degree of property diffusion of the monopolistic firm $\theta$. Comparative statics results are summarized by Figure 3. 
On the one hand, as $\theta$ increases, making property more diffuse and each owner's share smaller, the $I I$ locus rotates clockwise around point $(1+1 / \rho, 1+1 / \rho)$ and becomes flatter, reaching $\frac{\alpha_{2}}{\alpha_{1}}=1+1 / \rho$ as $\theta$ tends to 1 . Ceteris paribus, this makes region $N E$ larger (and region $S E$ smaller). On the other hand, the $I E^{o}$ locus rotates clockwise around point $(1,1+1 / \rho)$ and becomes flatter, also reaching $\frac{\alpha_{2}}{\alpha_{1}}=1+1 / \rho$ as $\theta$ tends to 1 . Ceteris paribus, this makes region $N W$ larger (and region $S W$ smaller).

In order to understand the effect of changes in $\theta$ on the $I I$ locus, notice that (13) can be rewritten as:

$$
\left[\rho \alpha_{1}-(1+\rho) \alpha_{0}\right]+(1 / \theta)\left[\rho\left(\alpha_{2}-\alpha_{1}\right)-(1+\rho)\left(\alpha_{1}-\alpha_{0}\right)\right]=0
$$

where the first term represents the net discounted gain (or loss) from innovation for capitalist households deriving from wage growth and the second term represents the net gain (loss) deriving from profit growth.

When the first term is negative (positive), an increase in $\theta$ implies that a higher (lower) net gain from profit growth is required for the above equation to be satisfied. For example, in region $S E$ innovation favors capitalists in terms of wages, but hurts them in terms of profits. Thus, when the weight of profit income decreases ( $\theta$ increases), a smaller gain from wage growth is necessary to compensate capitalists for the profit loss. Hence, region $S E$ shrinks as $\theta$ increases (given $\left(\alpha_{1}-\alpha_{0}\right),\left(\alpha_{2}-\alpha_{1}\right)$ must decrease).

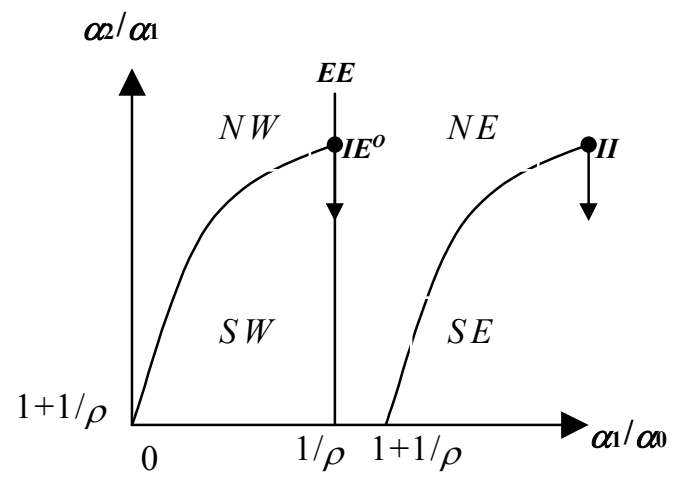

Figure 3: The equilibrium ( $\theta$ grows)

In the limit case where $\theta=1$ (i.e. the property of the firm is perfectly diffused), the $I E^{o}$ and $I I$ loci both collapse to $\alpha_{2} / \alpha_{1}=1+1 / \rho$, and the $E E$ locus becomes irrelevant since there are no 'pure' workers. Therefore, innovation always takes place and child labor disappears. 
In a different framework, Swinnerton and Rogers [15] [16] also discuss the relationship between firm property diffusion (equality) and child labor incidence. In their analysis, a reduction in inequality can raise poor families income above the subsistence level and permit them to withdraw chidren from work. Our point is quite different. More diffused property of the firm reduces child labor because it tends to remove the distributional conflict regarding innovation and education between workers and capitalists.

In the limit case where $\theta=0$, the $I E^{o}$ locus is no longer relevant and the $E E$ and $I I$ loci divide the space in three regions (see Figure 4). An equilibrium with (complete) child labor and no innovation occurs in all regions but one, that is the region to the right of $E E$ and above $I I$ (region $N E^{\prime}$ ), where the monopolistic firm innovates and workers send children to school. In region $S E^{\prime}$, that is to the right of $E E$ and below $I I$, child labor occurs because the monopolist resists innovation (profit after innovation are low relative to current one). In region $W$, that is to the left of $E E$ child labor occurs because workers are not willing to educate their children (wage growth following innovation is small).

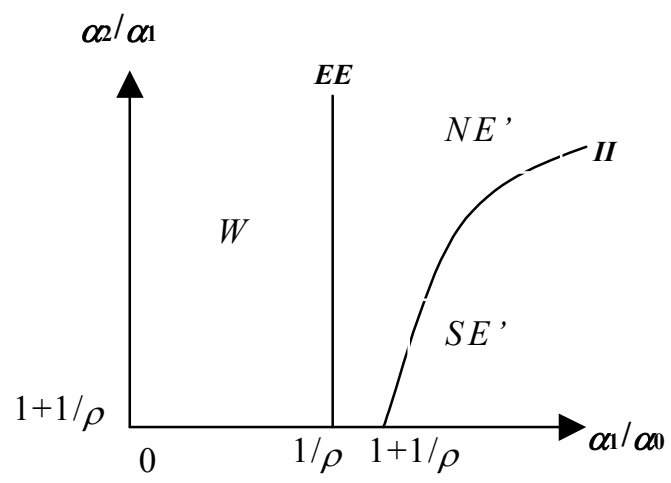

Figure 4: The equilibrium $(\theta=0)$

\section{Policy analysis}

Figure 2 reveals that there are three sources of inefficient child labor depending on the combinations of $\alpha_{1} / \alpha_{0}$ and $\alpha_{2} / \alpha_{1}$. In region $N W$ in equilibrium there is technological update but only capitalists educate their children ('elitarian push'). In region $S W$, workers' opposition to education forces all children to work ('educational impasse'). In region $S E$, it is capitalists' opposition to innovation that forces all children to work ('technological impasse'). Therefore, in all three regions there is scope for government intervention. 
To analyze government intervention, let us add an initial stage to the previous twostage game. In the initial stage, the government announces its economic policy (to which it is committed) in order to achieve the efficient allocation $\left(I, E^{o}, E\right)$. In the second and third stage, after being informed about government policy, capitalists and workers choose their optimal actions, in order to maximize their welfare.

As we have discussed above, in each region of Figure 2 the inefficiency of the equilibrium originates from different sources; thus, the appropriate government policy will depend on parameter values. In particular, since in regions $N W$ and $S W$ the inefficiency stems from the fact that workers do not find it worthwhile to educate their children, optimal intervention entails a subsidy to education financed through lump-sum taxation on capitalists (or, equivalently, on profits). Indeed, in both cases, universal education would allow the capitalists to fully reap the benefits of technological innovation, in terms of higher profits.

Differently, in region $S E$ the source of inefficiency is the capitalists' unwillingness to innovate. In this case optimal intervention entails a subsidy to innovation funded through lump-sum taxation on workers (or, equivalently, on wages).

Let us now calculate the minimum subsidy which implements the efficient allocation.

- Region $N W$ - Elitarian push:

Assume that the government announces that it will pay a subsidy to every household (whether capitalist or worker) which sends its children to school. The minimum net subsidy received by workers must be such that they are indifferent between outcome $\left(I, E^{o}, N E\right)$ and outcome $\left(I, E^{o}, E\right)$. Given the payoffs associated to these outcomes, straightforward calculations show that the total subsidy that has to be paid to all households is $S=$ $n\left(\alpha_{0}-\rho \alpha_{1}\right)$. Since this subsidy is financed through lump-sum taxation on profits, the net amount paid by capitalists (that is, the subsidy received by workers) is $(1-\theta) n\left(\alpha_{0}-\rho \alpha_{1}\right)$. Formally, if we denote the action of the government with $a^{g}$, we can write $a^{g}=\left(S, T_{\pi}\right)=$ $\left(n\left(\alpha_{0}-\rho \alpha_{1}\right), n\left(\alpha_{0}-\rho \alpha_{1}\right)\right)$ where $T_{\pi}$ is the tax on profit. It is immediate to show that given $a^{g}$, the equilibrium outcome of the three-stage game is $\left(I, E^{o}, E\right)$ and every player is at least as well off as in the two-stage game in which the government was inactive.

- Region $S W$ - Educational impasse:

Again, assume that the government pays a subsidy to every household which sends its children to school. The net subsidy received by workers must be such that they are indifferent between outcome $\left(N I, N E^{o}, N E\right)$ and outcome $\left(I, E^{o}, E\right)$. Thus, the total 
amount of the subsidy to be paid is $S=n\left(\alpha_{0}-\rho \alpha_{1}+\rho \alpha_{0}\right)$. This subsidy is financed through lump-sum taxation on profits. Thus the net amount paid by capitalists is (1$\theta) n\left(\alpha_{0}-\rho \alpha_{1}+\rho \alpha_{0}\right)$. In this case, $a^{g}=\left(S, T_{\pi}\right)=\left(n\left(\alpha_{0}-\rho \alpha_{1}+\rho \alpha_{0}\right), n\left(\alpha_{0}-\rho \alpha_{1}+\rho \alpha_{0}\right)\right)$. Again, given $a^{g}$, the equilibrium outcome of the three-stage game is $\left(I, E^{o}, E\right)$ and every player is at least as well off as in the two-stage game.

\section{- Region SE - Technological impasse:}

Now, assume that the government pays a subsidy to capitalists who innovate. The net subsidy received by capitalists must be such that they are indifferent between outcome $\left(N I, N E^{o}, N E\right)$ and outcome $\left(I, E^{o}, E\right)$. Since this subsidy is financed through lump-sum taxation on wages, it can be easily verified that the total amount of the subsidy to be paid is $S^{\prime} /(1-\theta)$ where:

$$
S^{\prime}=\left(\alpha_{1}-\alpha_{0}\right)(1+\rho-\theta \rho)+\theta \alpha_{0}-\rho\left(\alpha_{2}-\alpha_{1}\right)
$$

Once again, given $a^{g}=\left(S, T_{w}\right)=\left(S^{\prime} /(1-\theta), S^{\prime} /(1-\theta)\right)$, the equilibrium outcome of the three-stage game is $\left(I, E^{o}, E\right)$ and every player is at least as well off as in the two-stage game.

Our previous analysis can be used to evaluate one of the most commonly used form of intervention against child labor, namely compulsory education laws.

On the one hand, in regions $N W$ and $S W$, the implementation of legislative measures to eliminate child labor provides the firm with the right incentives to innovate. ${ }^{4}$ However, the resulting technological upgrade will benefit the owners of the monopolistic firm at the expenses of the workers who are forced to send their children to school. In this case, without any compensation to workers, legislative measures are not Pareto improving and imply a redistribution of income from workers to capitalists, where the latter enjoy the welfare gain from universal education at zero cost.

From a political economy perspective, the opportunity of such redistribution may justify the political (and economic) support of these measures by the owners of the firms. Weiner [17] discusses a historical example where the owners of the firms were in favor of the introduction of legislative measures against child labor. According to him "in India the proprietors of large businesses have not opposed child-labor laws... One of the complaints of managers of large firms is that their labor force is not sufficiently educated, that

\footnotetext{
${ }^{4}$ In this paper we abstract from the problem of enforceability and implementability of legislative measures. For an analysis of the role of legislation enforcement in the fight against child labor, see Bellettini and Berti Ceroni [4].
} 
too many workers are unable to read manuals or follow the simple instructions written on machines". Galor and Moav [10] provide several historical examples to argue that in the second phase of the Industrial Revolution "the capitalists were among the prime beneficiaries of the potential accumulation of human capital by the masses", so that they had the incentives to financially support public education.

On the other hand, notice that, in region $S E$, compulsory schooling legislation alone would bring about a welfare loss for all agents, since every child would be forced to go to school but firms would still not find it profitable to innovate. In this case, from a political point of view, legislative measures aimed at reducing the incidence of child labor would be hard to implement in the absence of innovation subsidies. ${ }^{5}$

\section{Conclusion}

By focusing on poverty and the determinants of the supply of child labor, a recent literature has tried to assess the welfare consequences of government intervention aimed at the reduction or elimination of the phenomenon. This paper adds to this literature by supplementing the analysis with an investigation of the determinants of the demand of the firm for child labor. More specifically, we study the relationship between technological innovation, education, and child labor in a setting where the returns to education depend on the level of technology and the profitability of technological upgrade depends on the quality of the labor force.

Our framework allows us to derive clear-cut welfare implications of public intervention in the area of child labor. In general, we have shown that legislative intervention (that is, child labor bans and compulsory education laws) cannot be Pareto improving unless some kind of redistribution from the owners of the firm to the workers also takes place. Moreover, there are cases where legislation alone decreases the welfare of all agents, since it does not provide the right incentives for the firm to innovate. In this case, the optimal policy would be to subsidize technological upgrade.

The simplicity of the framework also shows a potential for fruitful extensions. First, our model could be extended to a multi-period set-up. This would allow one to fully capture the long-run consequences of child labor and public intervention on human capital accumulation and economic development. Second, it could be enriched from a political economy point of view to investigate the role of different institutional mechanisms in mediating the conflicting interests of households and firms.

\footnotetext{
${ }^{5}$ Indeed, subsidies alone would achieve efficiency even without compulsory schooling legislation.
} 


\section{References}

[1] Baland, J-M. and J. A. Robinson (2000), "Is Child Labor Inefficient?", Journal of Political Economy, 108, 663-679.

[2] Basu, K. (1999), "Child Labor: Cause, Consequence, and Cure, with Remarks on International Labor Standards", Journal of Economic Literature, 37, 1083-1119.

[3] Basu, K. and P. H. Van (1998), "The Economics of Child Labor", American Economic Review, 88, 412-427.

[4] Bellettini, G. and C. Berti Ceroni (2000), "Compulsory Schooling Laws and the Cure Against Child Labor", University of Bologna, mimeo.

[5] Cigno, A. and F. Rosati (2000), "Why Do Indian Children Work, and Is It Bad For Them?", ChilD Working Paper, no.1.

[6] Dessy, S. E. (2000), "A Defense of Compulsory Measures Against Child Labor", Journal of Development Economics, 62, 261-275.

[7] Dessy, S.E. and S. Pallage (2001), "Child Labor and Coordination Failures", Journal of Development Economics, 65, 469-476.

[8] Dinopoulos E. and P. Segerstrom (1999), "A Schumpeterian Model of Protection and Relative Wages", American Economic Review, 89, 450-472.

[9] Galbi, D. A. (1997), "Child Labor and the Division of Labor in the Early English Cotton Mills", Journal of Population Economics, 10, 357-375.

[10] Galor, O. and O. Moav (2000), "Das Human Capital", Brown University Working Paper no. 2000-17.

[11] ILO (1998), Report VI (1): Child Labour: Targeting the intolerable, Geneva.

[12] Levy, V. (1985), "Cropping Pattern, Mechanization, Child Labor, and Fertility Behavior in a Farming Economy: Rural Egypt", Economic Development and Cultural Change, 33, 777-791.

[13] Murphy, K. M., Shleifer, A. and R. W. Vishny (1989), "Industrialization and the Big Push", Journal of Political Economy, 97, 1003-1026. 
[14] Ranjan, P. (2001), "Credit Constraints and the Phenomenon of Child Labor", Journal of Development Economics, 64, 81-102.

[15] Swinnerton, K. A. and C. A. Rogers (1999a), "The Economics of Child Labor: Comment", American Economic Review, 89(5), 1382-1385.

[16] Swinnerton, K. A. and C. A. Rogers (1999b), "Inequality, Productivity, and Child Labor: Theory and Evidence", mimeo.

[17] Weiner, M. (1991), The Child and the State in India: Child Labor and Education Policy in Comparative Perspective, Princeton: Princeton University Press. 
Appendix - The payoffs of the game

- Workers' payoffs

$A \equiv(1-\theta) \alpha_{0}(1+\rho n)$ associated to outcome $\left(N I, E^{o}, E\right)$

$B \equiv(1-\theta) \alpha_{0}(1+\rho n)$ associated to outcome $\left(N I, N E^{o}, E\right)$

$C \equiv(1-\theta) \alpha_{0}[1+(1+\rho) n]$ associated to outcome $\left(N I, E^{o}, N E\right)$

$D \equiv(1-\theta) \alpha_{0}[1+(1+\rho) n]$ associated to outcome $\left(N I, N E^{o}, N E\right)$

$K \equiv(1-\theta)\left(\alpha_{0}+\rho \alpha_{1} n\right)$ associated to outcome $\left(I, E^{o}, E\right)$

$F \equiv(1-\theta)\left(\alpha_{0}+\rho \alpha_{1} n\right)$ associated to outcome $\left(I, N E^{o}, E\right)$

$G \equiv(1-\theta) \alpha_{0}(1+n)$ associated to outcome $\left(I, E^{o}, N E\right)$

$H \equiv(1-\theta)\left[\alpha_{0}(1+n)+\rho \alpha_{1} n\right]$ associated to outcome $\left(I, N E^{o}, N E\right)$

- Capitalists' payoffs:

$$
\begin{aligned}
& A^{o} \equiv \theta \alpha_{0}(1+\rho n)+(1+\rho n)\left(\alpha_{1}-\alpha_{0}\right) \\
& B^{o} \equiv \theta \alpha_{0}[1+(1+\rho) n]+\left(\alpha_{1}-\alpha_{0}\right)[1+(\rho+\theta) n] \\
& C^{o} \equiv \theta \alpha_{0}(1+\rho n)+\left(\alpha_{1}-\alpha_{0}\right)[1+(1+\rho-\theta) n] \\
& D^{o} \equiv \theta \alpha_{0}[1+(1+\rho) n]+\left(\alpha_{1}-\alpha_{0}\right)[1+(1+\rho) n] \\
& K^{o} \equiv \theta\left(\alpha_{0}+\rho \alpha_{1} n\right)+\left(\alpha_{1}-\alpha_{0}\right)+\rho\left(\alpha_{2}-\alpha_{1}\right) n \\
& F^{o} \equiv \theta \alpha_{0}(1+n)+\left(\alpha_{1}-\alpha_{0}\right)(1+\theta n)+\rho\left(\alpha_{2}-\alpha_{1}\right)(1-\theta) n \\
& G^{o} \equiv \theta\left(\alpha_{0}+\rho \alpha_{1} n\right)+\left(\alpha_{1}-\alpha_{0}\right)[1+n(1-\theta)]+\rho\left(\alpha_{2}-\alpha_{1}\right) \theta n \\
& H^{o} \equiv \theta \alpha_{0}(1+n)+\left(\alpha_{1}-\alpha_{0}\right)(1+n)+\rho \theta \alpha_{1} n
\end{aligned}
$$

